\title{
Serum Soluble Tumor Necrosis Factor Receptor 1 Level is Associated with the Outcome of Diffuse Large B-Cell Lymphoma Patients Treated with the CHOP or R-CHOP Regimen
}

\author{
Naoe Goto, ${ }^{1,5}$ Hisashi Tsurumi, ${ }^{1)}$ Masao Takemura, ${ }^{2)}$ Takuro Matsumoto, ${ }^{1}$ Yuhei Shibata, ${ }^{1)}$ \\ Ryoko Mabuchi, ${ }^{1)}$ Nobuhiko Nakamura, ${ }^{1)}$ Hiroshi Nakamura, ${ }^{1)}$ Tetsuya Yamada, ${ }^{3)}$ \\ Mitsuru Seishima, ${ }^{2)}$ Tsuyoshi Takami, ${ }^{4,5)}$ Tamotsu Takeuchi, ${ }^{5)}$ and Hisataka Moriwaki ${ }^{1)}$
}

Diffuse large B-cell lymphoma (DLBCL) is a heterogeneous disease, with patients exhibiting a wide range of outcomes. Many investigators have searched for prognostic factors for DLBCL and, recently, the concentrations of several cytokines were identified to predict the clinical outcome of patients with aggressive non-Hodgkin's lymphomas, including DLBCL. Tumor necrosis factor receptor 1 (TNFR1), which is a member of the TNFR superfamily, has a soluble form (sTNFR1). In this study, we focused on sTNFR1 as a candidate prognostic factor that can be measured readily. We evaluated the prognostic significance of serum sTNFR1 in 213 patients with DLBCL (72 treated with CHOP and 141 with R-CHOP). In the CHOP-treated group, serum sTNFR1 concentration was one of the prognostic factors found. In the R-CHOP group, 5-year overall survival (OS) rates for those having sTNFR $1 \geq 4.25 \mathrm{ng} / \mathrm{mL}$ and $<4.25 \mathrm{ng} / \mathrm{mL}$ were $28.6 \%$ and $77.0 \%(\mathrm{p}<0.0001)$, and 5-year progression-free survival (PFS) rates were $26.7 \%$ and $69.2 \%(p<0.0001)$, respectively. In multivariate analyses, serum sTNFR1 was an independent prognostic factor for OS and PFS in the CHOP group. In the R-CHOP group, serum sTNFR1 was also an independent prognostic factor for both OS and PFS, as was poor PS for PFS. The prognosis of patients with high-intermediate risk or high risk, according to the International Prognostic Index, who also had high serum sTNFR1, was especially poor. Serum sTNFR1 level is a reliable prognostic factor for patients with DLBCL. [J Clin Exp Hematop 54(2) : 117-127, 2014]

Keywords: diffuse large B-cell lymphoma, lymphoma, prognostic factor, soluble tumor necrosis factor receptor 1

\section{INTRODUCTION}

The incidence of malignant lymphoma is reported as $1 /$ 10,000 people in Japan and exhibits an increasing trend. Diffuse large B-cell lymphoma (DLBCL) accounts for 30$40 \%$ of non-Hodgkin's lymphoma (NHL), being the most

Received: August 22, 2013

Revised : March 12, 2014

Accepted: April 10, 2014

${ }^{15}$ First Department of Internal Medicine, Gifu University Graduate School of Medicine, Gifu, Japan

${ }^{2)}$ Department of Informative Clinical Medicine, Gifu University Graduate School of Medicine, Gifu, Japan

${ }^{3}$ Department of Pathology, Gifu Municipal Hospital, Gifu, Japan

${ }^{4}$ Tokai Clinic, Gifu, Japan

${ }^{5)}$ Department of Immunopathology, Gifu University Graduate School of Medicine, Gifu, Japan

Corresponding author: Hisashi Tsurumi, M.D., First Department of Internal Medicine, Gifu University Graduate School of Medicine, 1-1 Yanagido, Gifu 501-1194, Japan

E-mail: htsuru@gifu-u.ac.jp common lymphoma in the Japanese population. On the basis of factors such as prognosis, pathology, and treatment response, DLBCL is a heterogeneous disease. Thus, the highrisk groups among patients with DLBCL need to be accurately identified to select an appropriate therapeutic strategy. Before the rituximab (R) era, the International Prognostic Index (IPI) was considered the standard index for patients with NHL treated with the CHOP regimen, consisting of cyclophosphamide (CPA), doxorubicin (DOX), vincristine (VCR), and prednisolone (PSL), or similar CHOP-like regimens. ${ }^{1}$ Since the introduction of $\mathrm{R}$, the R-CHOP regimen has become the standard treatment for patients with DLBCL. ${ }^{2-4}$ However, another concern subsequently arose regarding the utility of previously identified prognostic factors, such as the IPI, for prediction of the outcome of R-CHOP treatment.

Tumor necrosis factor (TNF) is one of the earliest cytokines to be produced in the inflammatory process, and plays a key role in initiating cytokine cascades. ${ }^{5}$ Furthermore, TNF 
and its receptors (TNFRs) are also important in the regulation of growth, differentiation, and/or apoptosis of malignant cells in chronic lymphocytic leukemia,${ }^{6}$ hairy cell leukemia, ${ }^{7}$ Hodgkin's lymphoma, and NHL. ${ }^{5}$ Two types of TNFR have been identified: 55-kDa (p55 TNFR; TNFR1) and 75-kDa varieties (p75 TNFR; TNFR2). While both receptors are simultaneously expressed to varying degrees on many cell types, activation of TNFR1 induces, through its intracellular death domain, the most common TNF responses, such as activation of nuclear factor- $\varkappa \mathrm{B}$, cell cytotoxicity, and proliferation, in contrast to TNFR2, which lacks the intracellular death domain. ${ }^{8}$ In addition, the extracellular domains of these two receptors can be cleaved into soluble TNFRs (sTNFR1, sTNFR 2$),{ }^{9}$ and then released into the serum. In this study, we focus on the relationship of sTNFR1, which has been well studied with regard to its activation and mechanisms in the common TNF activity cascade, with the prognosis of DLBCL patients.

\section{METHODS}

\section{Patients}

A total of 213 consecutive biopsy-confirmed DLBCL patients (122 males, 91 females) who were treated between September 1995 and June 2008 were enrolled in this study. None of the patients had previously been treated for DLBCL and none was infected with the human immunodeficiency virus or human T-cell lymphotropic virus type I. All cases were reclassified according to the World Health Organization (WHO) classification ${ }^{10}$ by three pathologists (TT, TY, and NG). R was introduced into our institution in October 2002. Between September 1995 and September 2002, 75 patients received chemotherapy that did not include rituximab (CHOP). Between December 2002 and June 2008, 144 patients received chemotherapy that did include it (R-CHOP). The clinical stage (CS) of the disease was evaluated according to the Ann Arbor classification, ${ }^{11}$ based on clinical findings and tumor measurements obtained before excisional biopsy. Mediastinal bulky disease was defined as a mediastinal mass with a maximal diameter exceeding one-third of the maximal chest diameter or any other mass $10 \mathrm{~cm}$ or more in maximal diameter. Staging and disease evaluation were based on results of the following procedures: physical examination; chest radiology; computed tomography or magnetic resonance imaging, if necessary, of the brain, neck, chest, abdomen, and pelvis; bone marrow aspiration and biopsy; gallium scintigraphy or fluorodeoxyglucose-positron emission tomography (FDG-PET) with computed tomography; and laboratory measurements of serum aspartate aminotransferase, total bilirubin, alkaline phosphatase, creatinine, lactate dehydrogenase (LDH), and peripheral blood counts. Patients who did not receive chemotherapy for any reason were excluded.
Table 1. Patient's characteristics

\begin{tabular}{lcccc}
\hline & \multicolumn{2}{c}{ CHOP } & \multicolumn{2}{c}{ R-CHOP } \\
\cline { 2 - 5 } & \multicolumn{2}{c}{$\mathrm{N}=72$} & \multicolumn{2}{c}{$\mathrm{N}=141$} \\
\hline Age, Median (range) & $67(22-80)$ & \multicolumn{2}{c}{$68(24-80)$} \\
\hline & $\mathrm{N}$ & $\%$ & $\mathrm{~N}$ & $\%$ \\
\hline Male & 43 & 59.7 & 79 & 56.0 \\
Age $>$ 60 & 47 & 65.3 & 104 & 73.8 \\
PS $>1$ & 22 & 30.5 & 29 & 20.6 \\
CS III/IV & 48 & 66.7 & 90 & 63.8 \\
Number of extra nodal sites $>1$ & 25 & 34.7 & 54 & 38.3 \\
Elevated LDH & 57 & 79.2 & 96 & 68.1 \\
IPI & & & & \\
$\quad$ Low risk & 10 & 13.9 & 33 & 23.4 \\
$\quad$ Low intermediate risk & 19 & 26.4 & 35 & 24.8 \\
$\quad$ High intermediate risk & 25 & 34.7 & 29 & 20.6 \\
$\quad$ High risk & 18 & 25.0 & 44 & 31.2 \\
\hline CHOP,
\end{tabular}

CHOP, cyclophosphamide, doxorubicin, vincristine, prednisolone; R-CHOP, rituximab, cyclophosphamide, doxorubicin, vincristine, prednisolone; PS, performance status; CS, clinical stage; IPI, International prognostic index; $\mathrm{LDH}$, lactate dehydrogenase

Our Institutional Review Board approved the study protocol. Written informed consent was obtained from each patient at study entry. The study was conducted in accordance with the human and ethical principles of research set forth in the Helsinki guidelines. Characteristics of the enrolled patients are presented in Table 1 .

\section{Serum STNFR1 determination}

To evaluate serum levels of sTNFR1, venous blood samples were drawn from patients immediately before the initiation of treatment. Serum sTNFR1 was determined using a sandwich enzyme-linked immunosorbent assay (ELISA) kit (BioSource sTNF-R1 ELISA kit, BioSource Europe SA, Nivelles, Belgium). The detection limit of the ELISA test was $0.05 \mathrm{ng} / \mathrm{mL}$. In healthy control subjects $(\mathrm{N}=21)$, the median sTNF-R1 level was $1.88 \mathrm{ng} / \mathrm{mL}$ (range 0.6 to 2.56 ). No significant differences in serum sTNFR1 levels were observed with respect to gender or age (data not shown).

\section{Treatment}

Patients in CS I received three cycles of CHOP $(\mathrm{N}=9)$ or R-CHOP therapy $(\mathrm{N}=16)$ followed by involved-field radiotherapy from 30 to $40 \mathrm{~Gy}$. Patients in CS II received six cycles of CHOP $(\mathrm{N}=15)$ or R-CHOP therapy $(\mathrm{N}=34)$. Patients in advanced CS (III or IV) received six or eight cycles of CHOP $(\mathrm{N}=48)$ or R-CHOP therapy $(\mathrm{N}=90)$. In advanced CS cases, except cases refractory to initial treatment, there was no difference in survival between patients who received six or eight cycles of CHOP or R-CHOP. The attending physician made the selection of six or eight cycles of treatment. All cases, except chemotherapy-refractory ones, 
completed the previously planned cycles of treatment. The standard CHOP regimen consisted of cyclophosphamide at $750 \mathrm{mg} / \mathrm{m}^{2}$ intravenously (IV), doxorubicin at $50 \mathrm{mg} / \mathrm{m}^{2} \mathrm{IV}$, and vincristine at $1.4 \mathrm{mg} / \mathrm{m}^{2}$ (maximum dose of $2.0 \mathrm{mg}$ ) IV on day 1 , and then prednisolone at $100 \mathrm{mg}$ orally on days 1 to 5. For patients enrolled after October $2002, \mathrm{R}$ at $375 \mathrm{mg} / \mathrm{m}^{2}$ IV was administered 2 days prior to each cycle of CHOP. After chemotherapy, patients with bulky disease underwent radiotherapy ranging from 30 to $40 \mathrm{~Gy}$. Patients who relapsed or whose disease progressed after CHOP or R-CHOP, and those who were resistant to $\mathrm{CHOP}$ or R-CHOP, received the P-IMVP-16/CBDCA (methylprednisolone, ifosfamide, methotrexate, etoposide, and carboplatin) regimen ${ }^{12}$ with or without $\mathrm{R}$ as a second-line therapy.

\section{Response criteria}

Tumor response was evaluated after cycles 2,4 , and 6 , and again after the final cycle of chemotherapy. Tumor progression at any of these time points indicated treatment failure. Responses to treatment were categorized after repeated physical examinations, radiological studies, gallium scintigraphy, and bone marrow aspiration, as defined by Cheson et $a .^{13}$

\section{Statistical analyses}

Data are expressed as the median and range and differences in median values were tested using the nonparametric Mann-Whitney $U$ test and the Bartlett test. The cut-off value for serum sTNFR1 was determined by a receiver operating characteristic analysis. Overall survival (OS) was measured from the start of chemotherapy until death from any cause. Progression-free survival (PFS) was measured from the start of chemotherapy until relapse or death from DLBCL. Univariate analyses of the effects of several pretreatment characteristics upon achieving complete remission (CR) were performed using the chi-square test. Univariate analyses of the effects of several pretreatment characteristics, including sTNFR1, upon survival were performed using the KaplanMeier method and log-rank test. A multivariate analysis was performed using the Cox proportional-hazards regression technique. $P$ values $<0.05$ indicated significance. All statistical analyses were conducted using JMP 7.0.2 (SAS Institute Inc., Cary, NC, USA).

\section{RESULTS}

\section{Characteristics of enrolled patients and serum STNFR1 levels in DLBCL}

In the CHOP group, the median serum sTNFR1 level was $3.32 \mathrm{ng} / \mathrm{mL}$ (range 1.06 to $38.31 \mathrm{ng} / \mathrm{mL}$ ), and in the R-CHOP group, $3.12 \mathrm{ng} / \mathrm{mL}$ (range 1.29 to $18.18 \mathrm{ng} / \mathrm{mL}$ ) (Table 2) (Fig. 1a). Various poor prognostic indicators were strongly associated with high serum sTNFR1 level, as follows: in the CHOP group, poor performance status (PS), advanced CS, and the existence of B symptoms (night sweats, fever, and body-weight loss); and in the R-CHOP group, advanced age, poor PS, elevated LDH, multiple extranodal involvement sites, advanced CS, the existence of B symptoms, and no achievement of CR (Table 2). Serum sTNFR1 levels significantly correlated with an increasing IPI score $(p=0.0021$ in the CHOP group and $p<0.0001$ in the R-CHOP group) (Table 2).

\section{Cut-off value for serum sTNFR1}

The cut-off value for sTNFR1 was determined by a receiver operating characteristic analysis to be $4.25 \mathrm{ng} / \mathrm{mL}$ (Fig. 1b).

\section{Serum STNFR1 on achievement of CR}

The CR rates of patients with sTNFR1 level $<4.25 \mathrm{ng} / \mathrm{mL}$ and $\geq 4.25 \mathrm{ng} / \mathrm{mL}$ were $79.6 \%$ and $57.7 \%$ in the CHOP group $(p=0.0475)$ and $83.7 \%$ and $55 \%$ in the R-CHOP group ( $p=$ $0.0005)$, respectively. In addition, the $\mathrm{CR}$ rate was significantly worse in patients having multiple extranodal involvement sites (> 1), advanced CS (III or IV), presence of B symptoms, unfavorable IPI score (high-intermediate [HI]- or high $[\mathrm{H}]$-risk groups) in the CHOP group, and advanced age, poor PS, elevated LDH, multiple extranodal involvement sites, unfavorable IPI, and poor revised IPI score in the RCHOP group (Table 3).

\section{Univariate analyses for effects of various factors on OS and PFS}

Patients with sTNFR1 level $<4.25 \mathrm{ng} / \mathrm{mL}$ and $\geq 4.25$ $\mathrm{ng} / \mathrm{mL}$ had 5 -year OS rates of $61.4 \%$ and $6.1 \%$ in the CHOP group $(p<0.0001)$ and $77.0 \%$ and $28.6 \%$ in the R-CHOP group $(p<0.0001)$, and PFS rates of $34.5 \%$ and $7.7 \%$ in the CHOP group $(p<0.0001)$ and $69.2 \%$ and $26.7 \%$ in the RCHOP group $(p<0.0001)$, respectively (Table 3 ; Fig. 1a, 1b; Fig. 2a, 2b). We then analyzed OS and PFS by separating limited- (CSI, II) from advanced-stage patients (CSIII, IV). The limited-stage patients with high sTNFR1 also had poorer OS and PFS than early-stage patients with low sTNFR1 (Fig. 1c, 1d; Fig. 2c, 2d), indicating that those with high sTNFR1 have a poor prognosis even in the limited-stage setting. In the CHOP group, the OS and PFS rates were significantly worse in elderly patients and patients with poor PS, multiple extranodal involvement sites, advanced CS, B symptoms, unfavorable IPI score, and no achievement of CR. Elevated LDH was a prognostic factor only for PFS (Table 3). 
Table 2. Serum soluble tumor necrosis factor receptor 1 (TNFR 1) level (ng/mL) according to some conventional prognostic factors

\begin{tabular}{|c|c|c|c|c|c|c|c|c|c|}
\hline \multirow[b]{2}{*}{ Factor } & & \multicolumn{4}{|c|}{ CHOP } & \multicolumn{4}{|c|}{ R-CHOP } \\
\hline & & No. & Median & Range & $p$-value & No. & Median & Range & $p$-value \\
\hline All patients & & 72 & 3.32 & $1.06-38.31$ & & 141 & 3.12 & $1.29-18.18$ & \\
\hline \multicolumn{10}{|l|}{ Gender } \\
\hline & Male & 43 & 3.36 & $1.32-38.31$ & N.S. & 79 & 3.13 & $1.47-18.18$ & N.S. \\
\hline & Female & 29 & 3.32 & $1.06-17.42$ & & 62 & 2.97 & $1.29-10.01$ & \\
\hline \multicolumn{10}{|l|}{ Age } \\
\hline & $<60$ & 25 & 3.22 & $1.35-17.42$ & N.S. & 37 & 2.33 & $1.29-13.51$ & $<0.0001$ \\
\hline & $\geq 60$ & 47 & 3.675 & $1.06-38.31$ & & 104 & 3.7 & $1.29-18.18$ & \\
\hline \multicolumn{10}{|c|}{ (1) } \\
\hline & 0,1 & 50 & 3.15 & $1.06-17.42$ & 0.0099 & 112 & 2.795 & $1.29-11.39$ & $<0.0001$ \\
\hline & $\geq 2$ & 22 & 5.75 & $1.68-38.31$ & & 29 & 5.24 & $2.13-18.18$ & \\
\hline \multicolumn{10}{|l|}{ LDH } \\
\hline & Normal & 15 & 3.22 & $1.9-38.31$ & N.S. & 45 & 2.37 & $1.29-5.81$ & 0.0002 \\
\hline & Elevated & 57 & 3.555 & $1.06-17.42$ & & 96 & 3.77 & $1.55-18.18$ & \\
\hline \multicolumn{10}{|c|}{ Extranodal sites } \\
\hline & 0,1 & 47 & 3.285 & $1.06-17.42$ & N.S. & 87 & 2.68 & $1.29-12.2$ & $<0.0001$ \\
\hline & $\geq 2$ & 25 & 3.9 & $1.68-38.41$ & & 54 & 4.365 & $1.35-18.18$ & \\
\hline \multicolumn{10}{|l|}{ CS } \\
\hline & I, II & 24 & 2.83 & $1.32-7.42$ & 0.0056 & 51 & 2.46 & $1.29-5.91$ & $<0.0001$ \\
\hline & III, IV & 48 & 3.74 & $1.06-38.41$ & & 90 & 3.91 & $1.29-18.18$ & \\
\hline \multicolumn{10}{|l|}{ IPI } \\
\hline & Low & 10 & 2.56 & $1.35-4.25$ & 0.0021 & 33 & 2.17 & $1.29-3.09$ & $<0.0001$ \\
\hline & Low-Intermedate & 19 & 3.32 & $1.32-17.42$ & & 35 & 2.85 & $1.35-5.91$ & \\
\hline & High-Intermedate & 25 & 3.205 & $1.06-10.19$ & & 29 & 5.085 & $1.5-18.18$ & \\
\hline & High & 18 & 5.93 & $1.68-38.31$ & & 44 & 8.7175 & $2.01-13.51$ & \\
\hline \multicolumn{10}{|l|}{ B symptom } \\
\hline & $(-)$ & 48 & 3.06 & $1.06-11.06$ & $<0.0001$ & 94 & 2.735 & $1.35-18.18$ & $<0.0001$ \\
\hline & $(+)$ & 24 & 6.61 & $2.26-38.31$ & & 47 & 5 & $1.29-13.51$ & \\
\hline \multicolumn{10}{|c|}{ Therapy response } \\
\hline & $\mathrm{CR}$ & 52 & 3.29 & $1.06-38.31$ & N.S. & 108 & 2.83 & $1.29-13.51$ & $<0.0001$ \\
\hline & not $\mathrm{CR}$ & 20 & 5.53 & $1.68-17.42$ & & 33 & 4.5 & $1.98-18.18$ & \\
\hline
\end{tabular}

CHOP, cyclophosphamide, doxorubicin, vincristine, prednisolone; R-CHOP, rituximab, cyclophosphamide, doxorubicin, vincristine, prednisolone; PS, performance status; LDH, lactate dehydrogenase; CS, clinical stage; IPI, International prognostic index; CR, complete remission; N.S., no significant difference

In the R-CHOP group, the OS and PFS rates were significantly worse in elderly patients and patients with poor PS, elevated LDH, multiple extranodal involvement sites, B symptoms, unfavorable IPI score, and no achievement of CR. Advanced CS was a prognostic factor for only PFS (Table 3).

\section{Multivariate analyses on $O S$ and PFS}

Multivariate analyses employing IPI-related factors and serum sTNFR1 level demonstrated that serum sTNFR1 was an independent prognostic factor for OS and PFS in the CHOP group. In the R-CHOP group, serum sTNFR1 was also an independent prognostic factor for both OS and PFS, as was poor PS for PFS (Table 4).

\section{Combination of IPI score and STNFR1 level on OS and PFS}

As demonstrated above, by univariate analysis, sTNFR1 was closely associated with the prognosis of DLBCL and, by multivariate analysis, had a higher propensity to associate with OS and PFS. Risk categories per IPI score were then divided into low- and high-sTNFR1 groups, resulting in four subgroups as follows: low and low-intermediate risk with high sTNFR1; low and low-intermediate risk with low sTNFR1; high-intermediate and high risk with high sTNFR1; and high-intermediate and high risk with low sTNFR1. As shown in Fig. 3, a highly significant difference was seen among these subgroups in both the CHOP and the R-CHOP groups. In particular, the high-intermediate- and high-risk with high-sTNFR1 subgroup had the poorest prognosis.

\section{DISCUSSION}

Before the R era, age, PS, CS, elevated LDH, and number of extranodal lesions were recognized as conventional prognostic factors incorporated into the IPI for patients with aggressive NHL. ${ }^{1}$ The IPI was based on patient characteristics that are directly associated with their condition, such as age and PS, and variables indirectly reflecting tumor biology, such as CS, LDH, and the number of extranodal involvement 
Table 3. Univariate analyses on remission rate and survival in diffuse large B-cell lymphoma

\begin{tabular}{|c|c|c|c|c|c|c|c|c|c|c|c|c|c|c|c|}
\hline \multirow{3}{*}{\multicolumn{2}{|c|}{ Factor }} & \multicolumn{7}{|c|}{ CHOP } & \multicolumn{7}{|c|}{ R-CHOP } \\
\hline & & \multirow{3}{*}{$\begin{array}{c}\text { No. } \\
47\end{array}$} & \multicolumn{2}{|c|}{ CR rate } & \multicolumn{2}{|c|}{ 5-year OS } & \multicolumn{2}{|c|}{ 5-year PFS } & \multirow{2}{*}{ No. } & \multicolumn{2}{|c|}{$\mathrm{CR}$ rate } & \multicolumn{2}{|c|}{ 5-year OS } & \multicolumn{2}{|c|}{ 5-year PFS } \\
\hline & & & $\%$ & $p$-value & $\%$ & $p$-value & $\%$ & $p$-value & & $\%$ & $p$-value & $\%$ & $p$-value & $\%$ & $p$-value \\
\hline \multirow{2}{*}{ sTNFR 1} & $<4.25 \mathrm{ng} / \mathrm{mL}$ & & 79.6 & \multirow{2}{*}{0.0475} & 61.4 & \multirow{2}{*}{$<0.0001$} & 34.5 & \multirow{2}{*}{$<0.0001$} & 103 & 83.7 & \multirow{2}{*}{0.0005} & 77.0 & \multirow{2}{*}{$<0.0001$} & 69.2 & \multirow{2}{*}{$<0.0001$} \\
\hline & $\geq 4.25 \mathrm{ng} / \mathrm{mL}$ & 25 & 57.7 & & 6.1 & & 7.7 & & 38 & 55.0 & & 28.6 & & 26.7 & \\
\hline \multirow{2}{*}{ Gender } & Male & 43 & 68.9 & \multirow{2}{*}{ N.S. } & 44.9 & \multirow{2}{*}{ N.S. } & 45.2 & \multirow{2}{*}{ N.S. } & 79 & 77.0 & \multirow{2}{*}{ N.S. } & 63.5 & \multirow{2}{*}{ N.S. } & 60.5 & \multirow{2}{*}{ N.S. } \\
\hline & Female & 29 & 75.6 & & 37.9 & & 41.5 & & 62 & 74.6 & & 65.7 & & 56.7 & \\
\hline \multirow{2}{*}{ Age } & $<60$ & 25 & 68.0 & \multirow{2}{*}{ N.S. } & 54.6 & 0026 & 54.7 & 00186 & 37 & 94.6 & 00005 & 82.3 & 00087 & 70.3 & 0045 \\
\hline & $\geq 60$ & 47 & 74.0 & & 36.7 & 0.026 & 31.8 & 0.0196 & 104 & 69.2 & 0.0005 & 58.6 & 0.0081 & 54.7 & 0.045 \\
\hline PS & 0,1 & 50 & 76.5 & NS & 51.7 & 00005 & 48.6 & 00003 & 112 & 84.5 & $000 \Omega 1$ & 71.1 & 00024 & 66.1 & ( \\
\hline PS & $\geq 2$ & 22 & 62.5 & N.S. & 25 & 0.0005 & 20.8 & 0.0003 & 29 & 46.8 & $<0.0001$ & 42.0 & 0.0024 & 28.0 & $<0.0001$ \\
\hline SOH & Normal & 15 & 86.7 & Is & 64.7 & I $\mathrm{G}$ & 57.3 & 0015 & 45 & 95.6 & - & 81.1 & 00100 & 68.8 & 002 \\
\hline LDH & Elevated & 57 & 68.3 & N.S. & 37.4 & N.S. & 35.1 & 0.0415 & 96 & 67.0 & $<0.0001$ & 56.9 & 0.0188 & 53.6 & 0.03 \\
\hline Extranodal & 0,1 & 47 & 81.3 & 00188 & 56 & 00085 & 51.7 & 00014 & 87 & 82.4 & 002 & 72.4 & 00242 & 65.6 & 0.0192 \\
\hline Sites & $\geq 2$ & 25 & 55.6 & 0.0188 & 18.7 & 0.0085 & 18.5 & 0.0014 & 54 & 66.1 & 0.02 & 52.5 & 0.0242 & 45.7 & 0.0192 \\
\hline & I, II & 24 & 95.8 & & 68.8 & & 64.7 & & 51 & 82.7 & & 74.8 & & 70.1 & \\
\hline $\mathrm{CS}$ & III, IV & 48 & 60.8 & & 30.7 & 0.0306 & 27.9 & 0.0395 & 90 & 71.4 & N.S. & 57.9 & N.S. & 51.3 & 0.0263 \\
\hline & Low & 10 & 100.0 & & 100 & & 100 & & 33 & 96.9 & & 86.8 & & 76.9 & \\
\hline IPI & Low-Intermedate & 19 & 73.7 & & 45.3 & $<00001$ & 39.9 & $<00001$ & 35 & 80.6 & $<00001$ & 68.6 & 00032 & 63.0 & 00009 \\
\hline IPI & High-Intermedate & 25 & 76.9 & 0.0106 & 44.1 & $<0.0001$ & 40.1 & $<0.0001$ & 29 & 82.8 & $<0.0001$ & 62.8 & 0.0032 & 64.2 & 0.0009 \\
\hline & High & 18 & 50.0 & & 10.9 & & 10 & & 44 & 52.2 & & 44.9 & & 36.6 & \\
\hline D onmetom & $(-)$ & 48 & 79.2 & 00303 & 59.1 & $-0 \Omega 001$ & 55 & -00001 & 94 & 80.3 & $\mathrm{NS}$ & 66.2 & $\mathrm{NS}$ & 58.4 & $\mathrm{NS}$ \\
\hline B symptom & $(+)$ & 24 & 54.2 & 0.0303 & 9.4 & $<0.0001$ & 8.8 & $<0.0001$ & 47 & 68.1 & N.S. & 58.2 & N.S. & 53.4 & N.S. \\
\hline Thernny responce & $\mathrm{CR}$ & 52 & & & 60.1 & $<00001$ & 55.2 & $<00001$ & 108 & & & 78.9 & $<0 \Omega 001$ & 70.8 & $<00001$ \\
\hline Therapy response & not CR & 20 & & & 0 & $<0.0001$ & 0 & $<0.0001$ & 33 & & & 19.0 & $<0.0001$ & 17.4 & $<0.0001$ \\
\hline & & & & & & & & & No. & $\mathrm{CR}$ rate & $p$-value & $\begin{array}{l}\text { 5-year } \\
\text { OS }\end{array}$ & $p$-value & $\begin{array}{l}\text { 5-year } \\
\text { PFS }\end{array}$ & $p$-value \\
\hline & & & & & & & Revised & Very Good & 7 & 100.0 & & 100.0 & & 68.6 & \\
\hline & & & & & & & IPI & Good & 61 & 87.0 & 0.0009 & 74.7 & 0.011 & 70.3 & 0.0295 \\
\hline & & & & & & & & Poor & 73 & 64.0 & & 52.1 & & 47.7 & \\
\hline
\end{tabular}

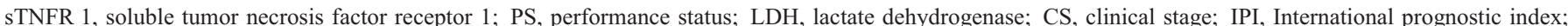

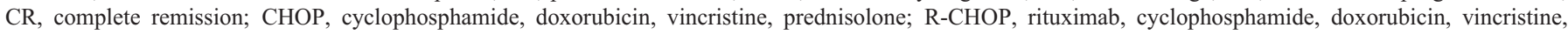
prednisolone; OS, overall survival; PFS, progression-free survival; N.S., no significant difference;

(a)

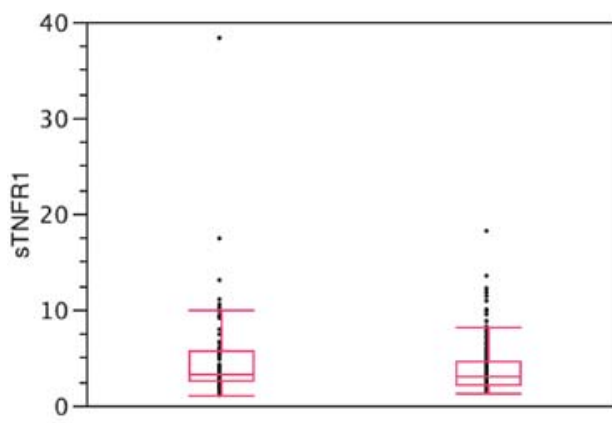

CHOP group R-CHOP group (b)

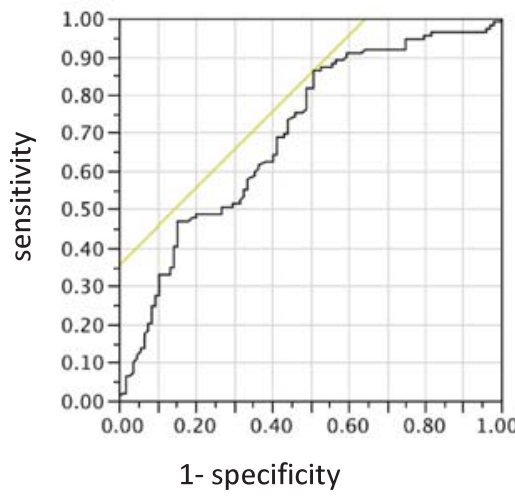

Fig. 1. Receiver operating characteristic curve and distributions of the value of measured soluble tumor necrosis factor receptor 1 (TNFR 1). (1a) Receiver operating characteristic curve shows that $4.25 \mathrm{ng} / \mathrm{mL}$ is a suitable cut-off (sensitivity $0.86,1$-specificity 0.3528 ). (1b) Distributions of the value of measured sTNFR 1 are shown (CHOP group, R-CHOP group). 
Table 4. Multivariate analyses on overall survival and progression free survival in diffuse large B-cell lymphoma patients

\begin{tabular}{|c|c|c|c|c|}
\hline \multirow{2}{*}{$\begin{array}{l}\text { CHOP } \\
<O S>\end{array}$} & \multirow[t]{2}{*}{ Odd's ratio } & \multicolumn{2}{|c|}{$95 \%$ confidence interval } & \multirow[t]{2}{*}{$p$-value } \\
\hline & & & & \\
\hline High sTNFR 1 & 3.99 & 1.97 & 8.1 & 0.0001 \\
\hline Age $>60$ & 1.45 & 0.7 & 3.16 & 0.318 \\
\hline Extranodal sites $>1$ & 1.12 & 0.54 & 2.4 & 0.757 \\
\hline $\mathrm{PS}>1$ & 1.51 & 0.73 & 3.09 & 0.26 \\
\hline Advanced CS & 1.83 & 0.81 & 4.21 & 0.14 \\
\hline \multicolumn{5}{|l|}{$<$ PFS $>$} \\
\hline Extranodal sites $>1$ & 1.12 & 0.53 & 2.4 & 0.8895 \\
\hline High sTNFR 1 & 3.63 & 1.81 & 7.35 & 0.0003 \\
\hline Age $>60$ & 1.51 & 0.72 & 3.31 & 0.664 \\
\hline Elavated LDH & 2.22 & 0.97 & 6.02 & 0.451 \\
\hline PS $>1$ & 1.64 & 0.79 & 3.4 & 0.608 \\
\hline Advanced CS & 2.17 & 0.93 & 5.21 & 0.461 \\
\hline R-CHOP & Odd's ratio & $95 \%$ & dence interval & $p$-value \\
\hline \multicolumn{5}{|l|}{$<\mathrm{OS}>$} \\
\hline High sTNFR 1 & 2.89 & 1.44 & 5.89 & 0.0029 \\
\hline Extranodal sites $>1$ & 1.03 & 0.53 & 2.03 & 0.6779 \\
\hline Age $>60$ & 2.11 & 0.94 & 5.66 & 0.0725 \\
\hline Elavated LDH & 1.19 & 0.53 & 2.87 & 0.6779 \\
\hline PS $>1$ & 1.52 & 0.76 & 2.94 & 0.6228 \\
\hline \multicolumn{5}{|l|}{$<$ PFS $>$} \\
\hline High sTNFR 1 & 2.39 & 1.26 & 4.56 & 0.008 \\
\hline Elavated LDH & 0.88 & 0.43 & 1.83 & 0.7498 \\
\hline $\mathrm{PS}>1$ & 2.15 & 1.16 & 3.93 & 0.0164 \\
\hline Extranodal sites $>1$ & 1.11 & 0.6 & 2.05 & 0.7498 \\
\hline Age $>60$ & 1.56 & 0.8 & 3.34 & 0.2001 \\
\hline
\end{tabular}

lesions. Beginning in 2000, using a cDNA microarray profiling method, patients with DLBCL were divided into two groups: those with a germ center B-cell type (GCB type) and those with an activated B-cell-like type (ABC type). ${ }^{14}$ The ABC-type patients had poorer prognosis than the GCB-type patients treated without R. Currently, the DNA microarray profiling method for patients with DLBCL is not available in most diagnostic pathology departments. Instead, immunohistochemistry is often used clinically as a prognostic tool. For example, Hans et al. ${ }^{15}$ showed that immunohistochemistry analysis for CD10, Bcl-6, and MUM-1 could be used to classify DLBCL into GCB and non-GCB subgroups, including $\mathrm{ABC}$ types, and was prognostically correlated with the groups defined by the cDNA microarray method. This immunohistochemical diagnostic method has been followed in some other studies. ${ }^{16-19}$

In the $\mathrm{R}$ era, prognostic factors were re-examined, and the utility of the IPI was validated in the R era by Ziepert et al. ${ }^{20}$ They reported that IPI retained its prognostic value in three prospective clinical trials with varying sample sizes. Sehn et $a l{ }^{21}$ reported that the revised IPI can discriminate patients with DLBCL into three prognostic groups : very good, good, and poor. However, both investigator teams reported that OS of the poor group was approximately $50 \%$. In order to select more strictly appropriate indications for various conventional, high-dose, and dose-dense regimens, including stem cell transplantation, the poorer prognostic groups (i.e., HI- and Hrisk groups according to the IPI before the $\mathrm{R}$ era) need to be discriminated with additional prognostic factors. As for DLBCL subtyping, the difference in the prognostic significance between the GCB type and the ABC type remains controversial in the $\mathrm{R}$ era. ${ }^{22-25}$

Examination of the cancer microenvironment has recently become a focus of clinical research. After performing clinical analyses on prognostic factors, some investigators suggested that serum levels of cytokines and their soluble receptors might reflect tumor growth and host responses. ${ }^{26,27}$ Recently, many studies on DLBCL by gene expression profiling have been carried out, and characteristic gene expression of microenvironment cells was also identified in a similar manner to that of tumor cells. In whole-genome arrays and multiple clustering analyses reported by Monti et al. ${ }^{28}$ and microarray 


\section{All clinical stage}

\section{Overall survival}

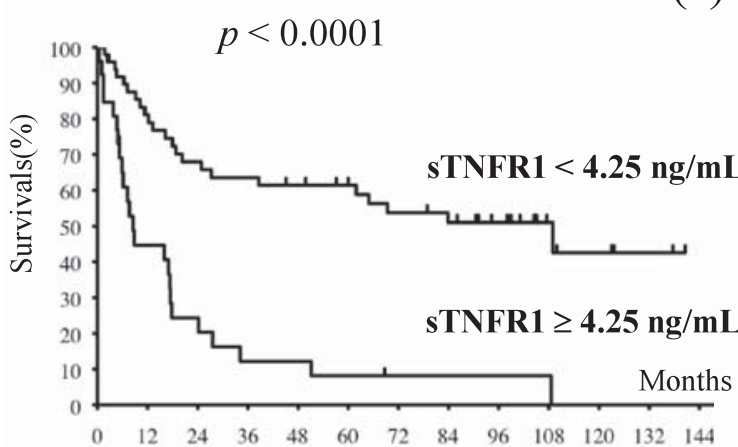

(a)
Progression-free survival

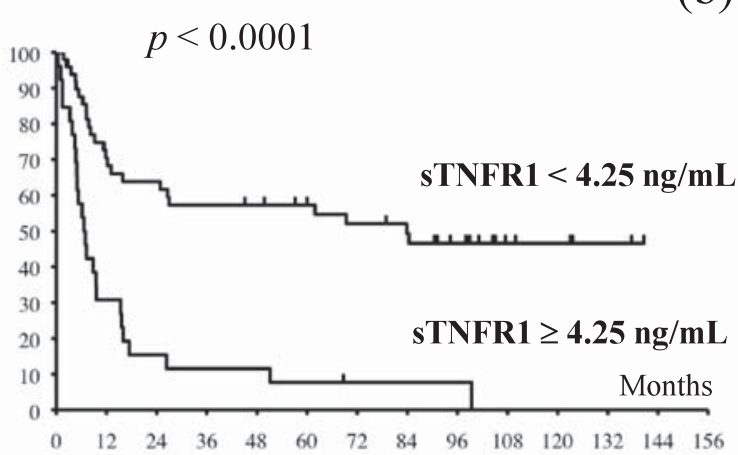

\section{Limited clinical stage}

Overall survival

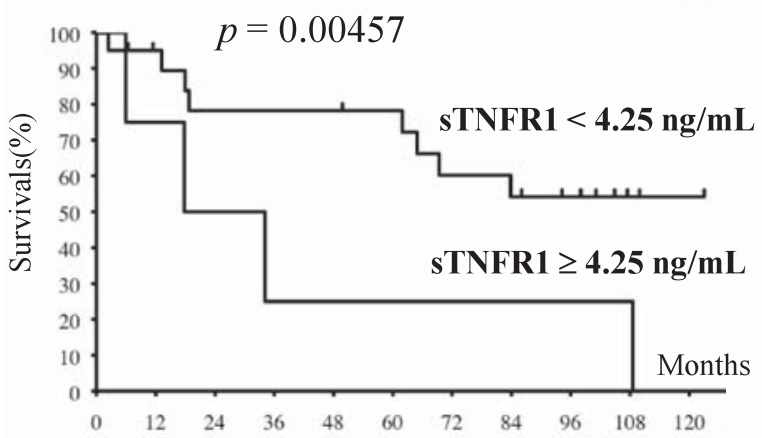

(c)
Progression-free survival

(d)

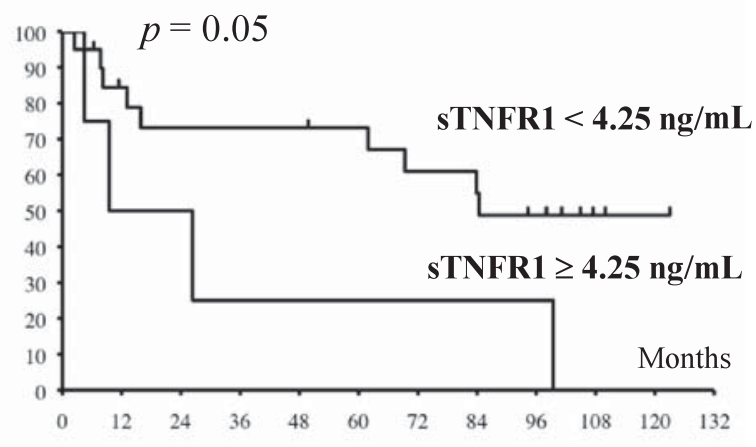

\section{Advanced clinical stage}

Overall survival

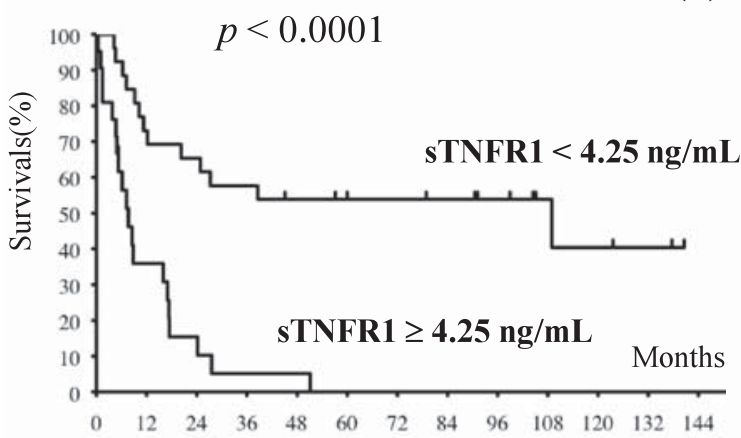

(e)
Progression-free survival

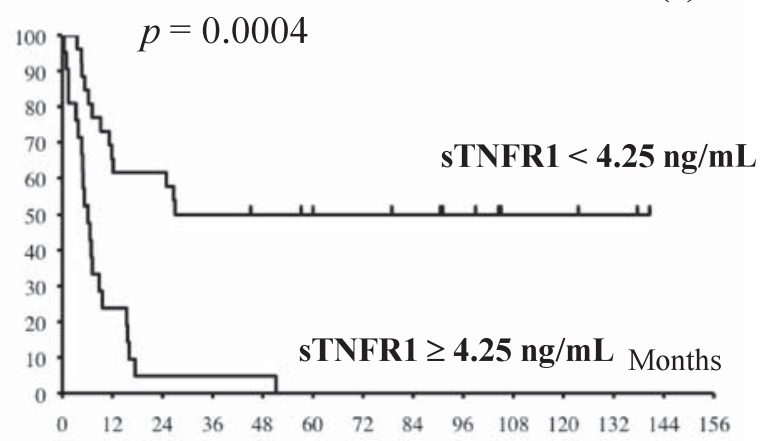

Fig. 2. Overall survival (OS) and progression-free survival (PFS) for diffuse large B-cell lymphoma (DLBCL) patients treated with CHOP. OS $(2 a)$ and PFS $(2 b)$ curves for DLBCL patients treated with CHOP using serum soluble tumor necrosis factor receptor 1 (TNFR1) levels of $<4.25 \mathrm{ng} / \mathrm{mL}$ and $\geq 4.25 \mathrm{ng} / \mathrm{mL}(p<0.0001$ for OS; $p$ $<0.0001$ for PFS). OS $(2 c)$ and PFS $(2 d)$ curves for patients with limited clinical stage $(p=0.00457$ for OS; $p=$ 0.05 for PFS). OS (2e) and PFS (2f) curves for patients with advanced clinical stage $(p<0.0001$ for OS; $p=0.0004$ for PFS). 


\section{All clinical stage}

Overall survival

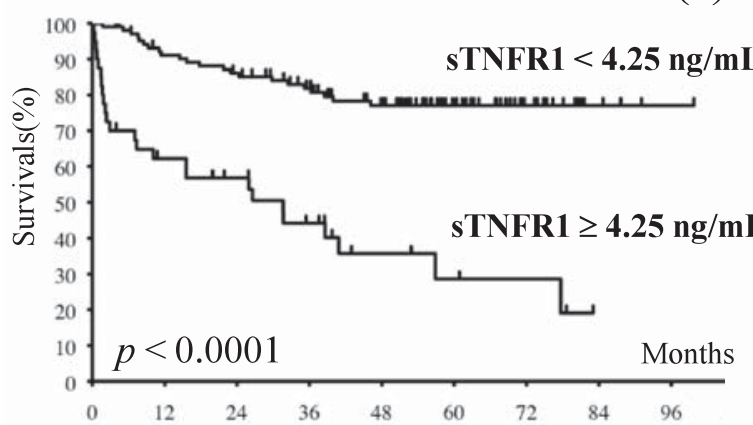

(a)
Progression-free survival

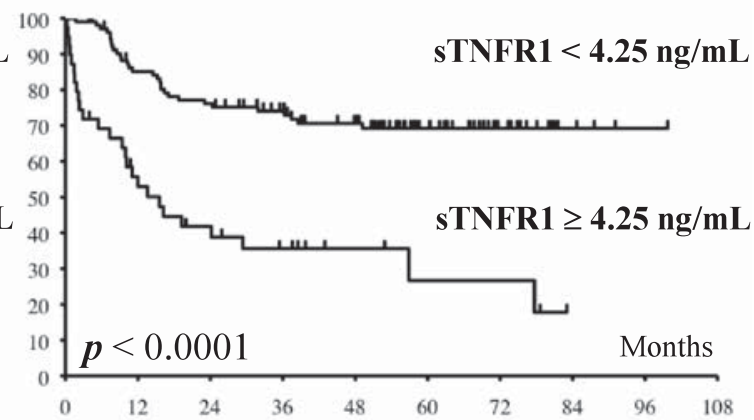

(b)

\section{Limited clinical stage}

Overall survival

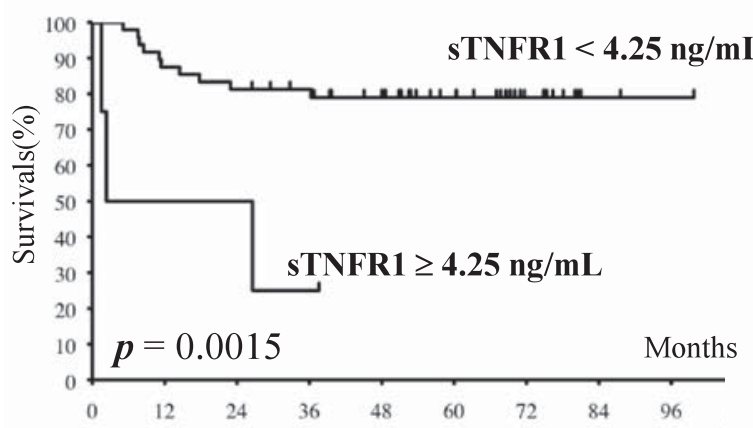

(c)

Progression-free survival

(d)

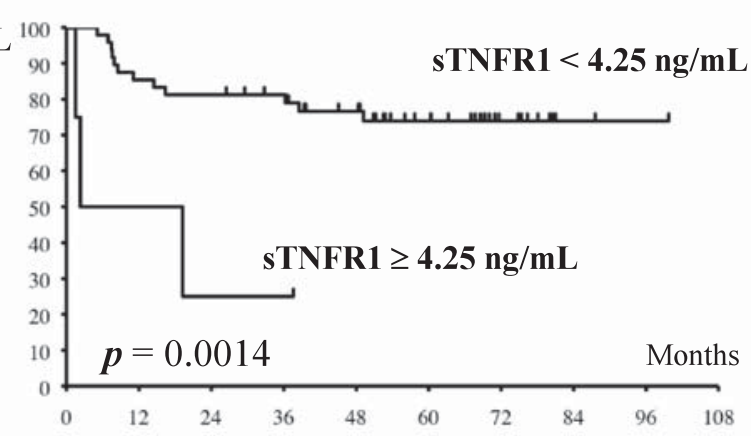

\section{Advanced clinical stage}

Overall survival

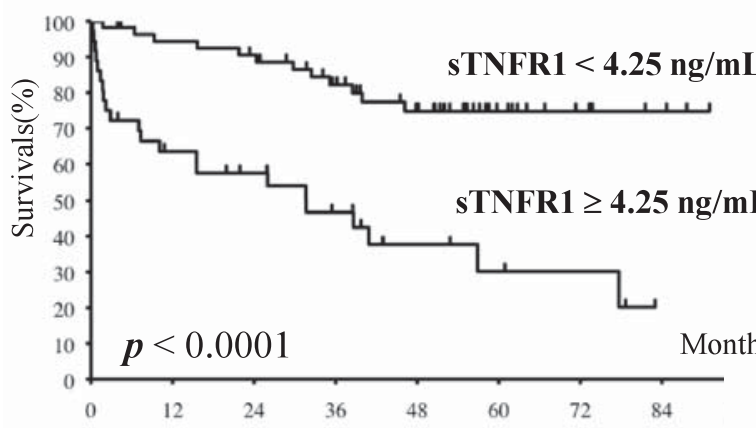

(e)

Progression-free survival

(f)

Fig. 3. Overall survival (OS) and progression-free survival (PFS) for diffuse large B-cell lymphoma (DLBCL) patients treated with R-CHOP. OS $(3 a)$ and PFS $(3 b)$ curves for DLBCL patients treated with R-CHOP using serum soluble tumor necrosis factor receptor 1 (TNFR1) levels of $<4.25 \mathrm{ng} / \mathrm{mL}$ and $\geq 4.25 \mathrm{ng} / \mathrm{mL}(p<0.0001$ for OS; $p<0.0001$ for PFS). OS (3c) and PFS (3d) curves for patients with limited clinical stage $(p=0.0015$ for OS; $p=$ 0.0014 for PFS). OS (3e) and PFS (3f) curves for patients with advanced clinical stage $(p<0.0001$ for OS; $p=$ 0.0004 for PFS). 

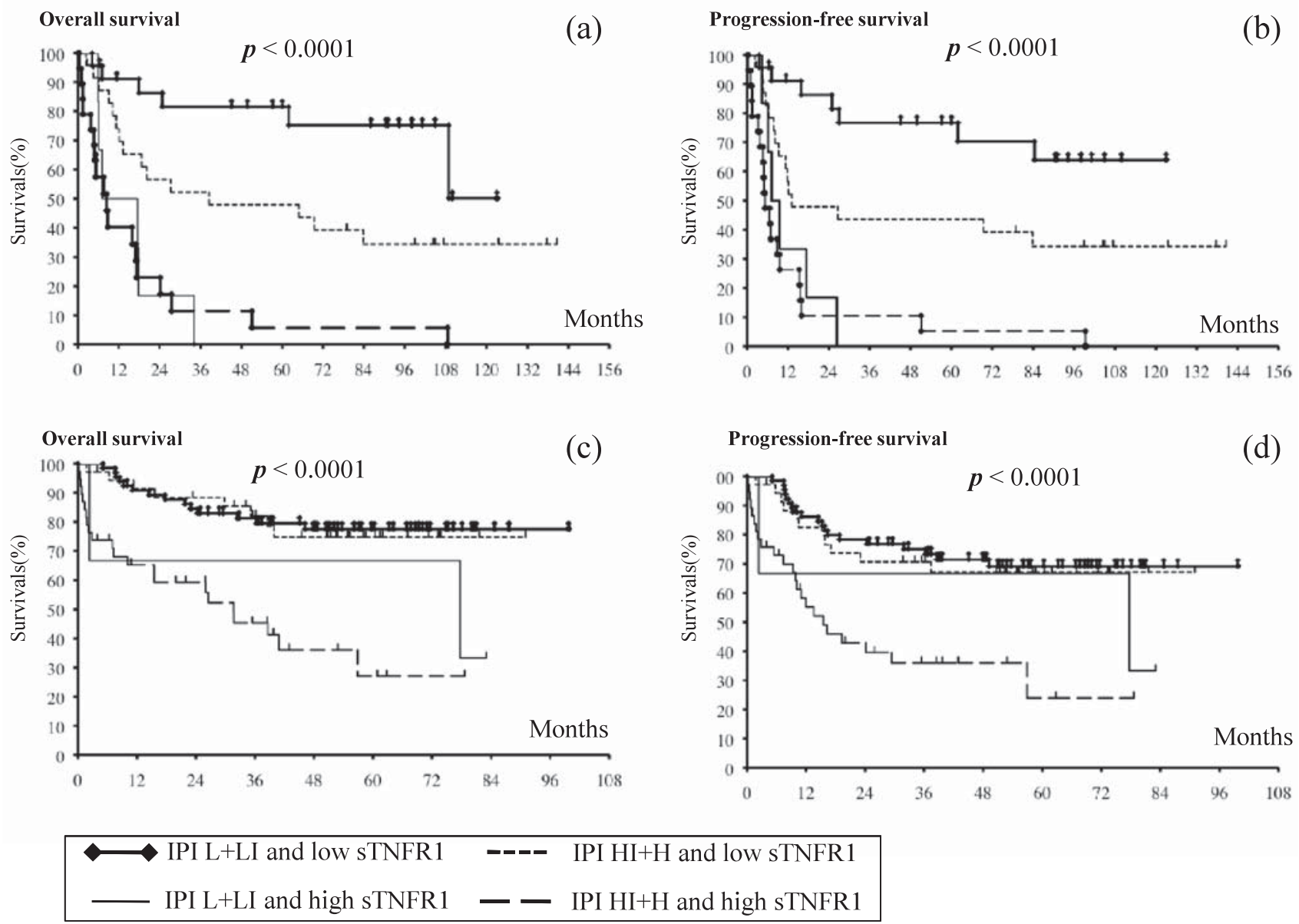

Fig. 4. OS (4a) and PFS (4b) curves in patients with diffuse large B-cell lymphoma (DLBCL) treated with CHOP, classified according to the combination of International Prognostic Index (IPI) results and soluble tumor necrosis factor receptor 1 (sTNFR1) level. OS (4c) and PFS (4d) curves in DLBCL patients treated with R-CHOP, classified according to the combination of IPI results and sTNF-R1 level. L, low-risk group; LI, low-intermediate-risk group; HI, high-intermediate-risk group; H, high-risk group

expression profiling of apoptosis-related genes reported by Muris et al., ${ }^{29}$ TNFRSF1A, the gene for TNFR1, was identified in the DLBCL cohort. In both reported studies, TNFRSF1A was found to be upregulated as a molecule related to an immune response rather than to the tumor growth per se. Therefore, we hypothesized that serum sTNFR1 was related to an immune reaction against lymphoma. TNFRSF1B, the gene of TNFR2, and the TNF receptorassociated death domain (TRADD) gene are also similarly expressed in DLBCL. TRADD is an intracellular death domain that directly binds to only TNFR1, but not to TNFR2. This finding suggests that common activation of the TNF cascade through TNFR1 is closely related to the immune response against the tumor. Soluble TNFR1 is shed from the cell surface due to cell activation, ${ }^{8}$ thus reflecting the immune response. The IPI contains factors that reflect tumor growth (CS, LDH, extranodal sites) and factors that reflect a patient's ability to tolerate intensive therapy (age and PS), but no factors that reflect the immune response to lymphoma. In our analysis, sTNFR1 was a strong and independent prognostic factor from each index of IPI both before and after the R era. In addition, we found a more prognostically poor subgroup (high-intermediate and high risk by IPI score and high-serum sTNFR1) by using a combination of sTNFR1 and IPI results, even in the R-CHOP group. Refractory or relapsed cases after R-CHOP do not have a good response to salvage therapy ${ }^{30-32}$ If we could predict refractory or relapsed cases before initial R-CHOP therapy, these cases could possibly be given an alternative therapy for improved prognosis.

It is difficult to use sTNFR1, which is a continuous variable, to determine a precise prognostic cut-off value. However, its measurement, as a prognostic factor, is simple and inexpensive when compared with gene expression profiling and FDG-PET. Therefore, we think those problems of 
cut-off determination could be resolved by examining an increased number of cases.

In conclusion, serum sTNFR1 might be a significant prognostic factor for patients with DLBCL treated with either $\mathrm{CHOP}$ or R-CHOP regimens. The current findings should be confirmed in other patient cohorts in the future in order to reach more definitive conclusions regarding differences among various patient subgroups. The most reliable prognostic factor and the best combination of some prognostic factors for DLBCL should be further clarified in order to assist in selecting the appropriate rituximab-based treatment regimen.

\section{REFERENCES}

1 The International Non-Hodgkin's Lymphoma Prognostic Factors Project: A predictive model for aggressive non-Hodgkin's lymphoma. N Engl J Med 329:987-994, 1993

2 Coiffer B, Lepage E, Briere J, Herbrecht R, Tilly H, et al:: CHOP chemotherapy plus rituximab compared with $\mathrm{CHOP}$ alone in elderly patients with diffuse large- B-cell lymphoma. N Engl J Med 346:235-242, 2002

3 Fisher RI, Shah P: Current trends in large cell lymphoma. Leukemia 17:1948-1960, 2003

4 Pfreundschuh M, Trümper L, Osterborg A, Pettengell R, Trneny M, et al.: MabThera International Trial Group. CHOP-like chemotherapy plus rituximab versus CHOP-like chemotherapy alone in young patients with good-prognosis diffuse large-B-cell lymphoma: a randomised controlled trial by the MabThera International Trial (MInT) Group. Lancet Oncol 7:379-391, 2006

5 Ruco LP, Pomponi D, Pigott R, Stoppacciaro A, Monardo F, et $a l .:$ Cytokine production (IL-1 $a, \mathrm{IL}-1 \beta$, and TNFa) and endothelial cell activation (ELAM-1 and HLA-DR) in reactive lymphadentis, Hodgkin's disease, and in non-Hodgkin's lymphomas. An immunocytochemical study. Am J Pathol 137:1163-1171, 1990

6 Digel W, Stefanic M, Schöniger W, Buck C, Raghavachar A, et al.: Tumor necrosis factor induces proliferation of neoplastic B cells from chronic lymphocytic leukemia. Blood 73:1242-1246, 1989

7 Trentin L, Zambello R, Agostini C, Siviero F, Adami F, et al:: Expression and functional role of tumor necrosis factor receptors on leukemic cells from patients with type B chronic lymphoproliferative disorders. Blood 81:752-758, 1993

8 Nophar Y, Kemper O, Brakebusch C, EngelmannH, Zwang R, et al.: Soluble forms of tumor necrosis factor receptors (TNF-Rs). The cDNA for the type I TNF-R, cloned using amino acid sequence data of its soluble form, encodes both the cell surface and a soluble form of the receptor. EMBO J 9:3269-3278, 1990

9 Micheau O, Tschopp J: Induction of TNF receptor I-mediated apoptosis via two sequential signaling complexes. Cell 114:181190, 2003

10 WHO Classification of Tumours, Tumours of Haematopoietic and Lymphoid Tissues. Swerdlow SH, Campo E, Harris NL, Jaffe ES,
Pileri SA, et al. (eds): 4th ed, Lyon, IARC, 2008

11 Carbone PP, Kaplan HS, Musshoff K, Smithers DW, Tubiana M: Report of the committee on Hodgkin's disease Staging Classification. Cancer Res 31:1860-1861, 1971

12 Sawada M, Tsurumi H, Yamada T, Hara T, Fukuno K, et al.: A prospective study of P-IMVP- 16/CBDCA: a novel salvage chemotherapy for patients with aggressive non-Hodgkin's lymphoma who had previously received CHOP therapy as first-line chemotherapy. Eur J Haematol 68:354-361, 2002

13 Cheson BD, Horning SJ, Coiffer B, Shipp MA, Fisher RI, et al.: Report of an international workshop to standardize response criteria for non-Hodgkin's lymphomas. NCI Sponsored International Working Group. J Clin Oncol 17:1244-1253, 1999

14 Alizadeh AA, Eisen MB, Davis RE, Ma C, Lossos IS, et al.: Distinct types of diffuse large B-cell lymphoma identified by gene expression profiling. Nature 403:503-511, 2000

15 Hans CP, Weisenburger DD, Greiner TC, Gascoyne RD, Delabie $\mathrm{J}$, et al:: Confirmation of the molecular classification of diffuse large B-cell lymphoma by immunohistochemistry using a tissue microarray. Blood 103:275-282, 2004

16 Colomo L, López-Guillermo A, Perales M, Rives S, Martínez A, et al:: Clinical impact of the differentiation profile assessed by immunophenotyping in patients with diffuse large B-cell lymphoma. Blood 101:78-84, 2003

17 Muris JJ, Meijer CJ, Vos W, van Krieken JH, Jiwa NM, et al.: Immunohistochemical profiling based on Bcl-2, CD10 and MUM1 expression improves risk stratification in patients with primary nodal diffuse large B cell lymphoma. J Pathol 208:714-723, 2006

18 Choi WW, Weisenburger DD, Greiner TC, Piris MA, Banham $\mathrm{AH}$, et al:: A new immunostain algorithm classifies diffuse large B-cell lymphoma into molecular subtypes with high accuracy. Clin Cancer Res 15:5494-5502, 2009

19 Meyer PN, Fu K, Greiner TC, Smith LM, Delabie J, et al.: Immunohistochemical methods for predicting cell of origin and survival in patients with diffuse large B-cell lymphoma treated with rituximab. J Clin Oncol 29:200-207, 2011

20 Ziepert M, Hasenclever D, Kuhnt E, Glass B, Schmitz N, et al.: Standard International prognostic index remains a valid predictor of outcome for patients with aggressive $\mathrm{CD} 20^{+} \mathrm{B}$-cell lymphoma in the rituximab era. J Clin Oncol 28:2373-2380, 2010

21 Sehn LH, Berry B, Chhanabhai M, Fitzgerald C, Gill K, et al.: The revised International Prognostic Index (R-IPI) is a better predictor of outcome than the standard IPI for patients with diffuse large B-cell lymphoma treated with R-CHOP. Blood 109:18571861, 2007

22 Saito B, Shiozawa E, Usui T, Nakashima H, Maeda T, et al.: Rituximab with chemotherapy improves survival of non-germinal center type untreated diffuse large B-cell lymphoma. Leukemia 21:2563-2566, 2007

23 Winter JN, Weller EA, Horning SJ, Krajewska M, Variakojis D, et al.: Prognostic significance of $\mathrm{Bcl}-6$ protein expression in DLBCL treated with CHOP or R-CHOP. A prospective correlative study. Blood 107:4207-4213, 2006 


\section{Serum sTNFR1 for DLBCL}

24 Costa LJ, Feldman AL, Micallef IN, Inwards DJ, Johnston PB, et al.: Germinal center B (GCB) and non- GCB cell-like diffuse large B cell lymphomas have similar outcomes following autologous haematopoietic stem cell transplantation. Br J Haematol 142: 404-412, 2008

$25 \mathrm{Fu} \mathrm{K}$, Weisenburger DD, Choi WW, Perry KD, Smith LM, et al.: Addition of rituximab to standard chemotherapy improves the survival of both the germinal center B-cell-like and non-germinal center B-cell-like subtypes of diffuse large B-cell lymphoma. J Clin Oncol 26:4587-4594, 2008

26 Alizadeh AA, Gentles AJ, Alencar AJ, Liu CL, Kohrt HE, et al.: Prediction of survival in diffuse large B-cell lymphoma based on the expression of 2 genes reflecting tumor and microenvironment. Blood 118:1350-1358, 2011

27 Lenz G, Wright G, Dave SS, Xiao W, Powell J, et al:: Stromal gene signatures in large-B-cell lymphomas. N Engl J Med 359: 2313-2323, 2008

28 Muris JJ, Ylstra B, Cillessen SA, Ossenkoppele GJ, KluinNelemans JC, et al: : Profiling of apoptosis genes allows for clini- cal stratification of primary nodal diffuse large B-cell lymphomas. Br J Haematol 136:38-47, 2007

29 Monti S, Savage KJ, Kutok JL, Feuerhake F, Kurtin P, et al.: Molecular profiling of diffuse large B-cell lymphoma identifies robust subtypes including one characterized by host inflammatory response. Blood 105:1851-1861, 2005

30 Matasar MJ, Czuczman MS, Rodriguez MA, Fennessy M, Shea TC, et al.: Ofatumumab in combination with ICE or DHAP chemotherapy in relapsed or refractory intermediate grade B-cell lymphoma. Blood 122:499-506, 2013

31 Cuccuini W, Briere J, Mounier N, Voelker HU, Rosenwald A, et al:: $\mathrm{MYC}^{+}$diffuse large B-cell lymphoma is not salvaged by classical R-ICE or R-DHAP followed by BEAM plus autologous stem cell transplantation. Blood 119:4619-4624, 2012

32 Gisselbrecht C, Glass B, Mounier N, Singh Gill D, Linch DC, et al:: Salvage regimens with autologous transplantation for relapsed large B-cell lymphoma in the rituximab era. J Clin Oncol 28:41844190, 2010 